\title{
Avaliação de mudança em mulheres vítimas de violência'
}

\author{
Evaluation of change in women victims of violence
}

\author{
Juliana Tavares Guzzon ${ }^{[a]}$, Elisa Medici Pizão Yoshida ${ }^{[b]}$
}

\footnotetext{
${ }^{[a]}$ Mestre em Psicologia pela Pontifícia Universidade Católica de Campinas (PUCCampinas), Campinas, SP Brasil, e-mail:

ju_guzzon@yahoo.com.br

${ }^{[b]}$ Doutora em Psicologia Clínica pela Universidade de São Paulo (USP), docente do Programa de Pós-graduação Stricto Sensu em Psicologia da Pontifícia Universidade Católica de Campinas (PUC-Campinas), Campinas, SP - Brasil, e-mail: eyoshida@puc-campinas.edu.br
}

Recebido: 23/02/2012 Received: 02/23/2012

Aprovado: 03/04/2012 Approved: 04/03/2012

\begin{abstract}
Resumo
Mulheres vítimas de violência são assistidas por diferentes instituições, entretanto a qualidade das mudanças que apresentam geralmente é desconhecida. 0 objetivo da pesquisa foi avaliar mudanças em aspectos psicológicos de mulheres vítimas de violência em fase final de atendimento quando comparadas com mulheres em início de atendimento, em uma organização não governamental. Compuseram a amostra um grupo pré-assistência (Gr. 1), com nove mulheres, $\mathrm{M}=$ 36,7, d.p. = 8,68 anos, e um grupo pós-assistência (Gr. 2), com nove mulheres, com idade $M=41$, d.p. $=11,28$ anos. Foram avaliadas com a Escala de Avaliação de Sintomas (EAS-40), Escala de Estágio de Mudança (EEM) e Escala Diagnóstica Adaptativa Operacionalizada Redefinida(EDAO-R). Os resultados apontaram melhora na eficácia da adaptação e nos sintomas psicopatológicos, que se mantiveram severos. Não houve alterações nos estágios de mudança. Sugerem-se adequação dos atendimentos às necessidades psicológicas das mulheres e realização de pesquisas sistemáticas de acompanhamento dos resultados.
\end{abstract}

Palavras-chave: Violência contra mulher. Avaliação psicológica. Mudança em psicoterapia.

\begin{abstract}
Women victims of violence are assisted by different institutions with different types of intervention, however, the quality of changes that is presented are not always recognized. The aim of this study was to evaluate changes in the psychological aspects of women who are victim of violence before being assisted and compare them to those women who have already been assisted by the institution. The sample comprised of a group pre-assistance (Gr. 1), with nine women, $M=36.7$, d.p. = 8.68 years old, and a group post-assistance (Gr. 2), with nine women, $M=41$, d.p. $=11.28$ years old. They were evaluated with the scale of symptoms (EAS-40), Stage of Change Scale (EEM) and Operational Adaptive Diagnostic Scale Redefined (EDAO-R). The results indicated improvement in the effectiveness of adaptation and psychopathological symptoms, which nevertheless remained severe. No change in stages of
\end{abstract}

\footnotetext{
1 Apoio: CNPq. Este trabalho é derivado da Dissertação de Mestrado defendida pela primeira autora, sob a orientação da segunda autora, junto ao Programa de Pós-graduação Stricto Sensu em Psicologia da Pontifícia Universidade Católica de Campinas.
}

Psicol. Argum. 2013 jul./set., 31 (74), 415-423 
change. Suggestions are made to fit the psychological needs of the care of women and implementation of systematic research to monitor the results.

Keywords: Violence against women. Psychological evaluation. Change in psychotherapy.

\section{Iniciativas institucionais para combater a violência contra a mulher no Brasil}

Foi principalmente a partir da década de 1970 que o movimento feminista brasileiro se expandiu e passou a defender o reconhecimento da violência contra a mulher como um problema social (Cortizo \& Goyeneche, 2010; Jacobucci, 2004). O estado apresentou como resposta a essa demanda a criação e implementação, em São Paulo, da Delegacia Especializada de Atendimento à Mulher (DEAM), em 1985 e, nos anos 1990, a criação dos Juizados Especiais Cíveis e Criminais (JECRIMs), regidos pela Lei n. 9.099/95. Houve, também, a implantação de Casas-Abrigo para as mulheres vítimas de violência que correm risco de vida caso voltem para suas casas. Dessa forma, a violência contra a mulher, inicialmente um problema de esfera privada, passou a ser considerada um problema de ordem pública e política (Bandeira, 2009; Jacobucci, 2004).

A intensa atuação dos movimentos feministas e das mulheres foi de suma importância para pressionar o Estado brasileiro, fazendo-o aprovar, em 2006, a Lei n. 11.340, ou Lei Maria da Penha, que tem por objetivo criar mecanismos para coibir, prevenir e punir a violência doméstica e familiar contra a mulher (Bandeira, 2009; Cortizo \& Goyeneche, 2010). De acordo com Dantas e Méllo (2008), a Lei n. 11.340 possibilitou que a violência doméstica e familiar contra a mulher fosse definida como um crime específico, causando interesse no debate público e uma transformação simbólica no conceito de violência contra a mulher, que deixa de ser entendida como crime de menor potencial ofensivo.

No entanto, apenas a promulgação da lei não é suficiente para acabar com todos os entraves. Há que se contar com políticas públicas e instituições do Estado bem aparelhadas que garantam a eficácia e eficiência da lei, bem como uma nova cultura democrática com valores renovados que não aprisionem as mulheres em papéis imaginários, o que em si mesmo constitui mais uma forma de violência (Cortizo \& Goyeneche, 2010; Pougy, 2010). Da mesma forma, é necessário compreender claramente e em profundidade os entraves e obstáculos de natureza psicológica que as mulheres precisam superar para se beneficiarem da assistência prestada.

Isto é, não são suficientes leis e instituições de proteção à mulher se ela não puder assumir um papel ativo na condução de seu destino e romper com os padrões de relacionamento que a mantêm vítima de companheiro violento. Ou ainda, se não for capaz de superar o sofrimento mental que se manifesta, no mais das vezes como sintomas psicopatológicos, tais como, ansiedade, depressão, ideias paranoides, hostilidade, pensamentos repetitivos, sintomas de natureza somática, entre outros. Dito de outra forma, o sucesso de qualquer programa de assistência a mulheres vítimas de violência passa necessariamente pela compreensão das condições emocionais, dos recursos adaptativos e da consciência que elas têm de que sua condição pode ser modificada.

Dentre as várias instituições criadas no sentido de oferecer assistência adequada às mulheres vítimas de violência, destaca-se aqui o papel desempenhado pela SOS Ação Mulher e Família. Essa organização não governamental, situada em cidade do interior de São Paulo, sem fins lucrativos, presta atendimento às mulheres e suas famílias, vítimas de violência doméstica e sexual, por meio de programas de intervenção interdisciplinar de advogados, psicólogos e assistentes sociais.

Mulheres que chegam à instituição passam, primeiramente, por um grupo Interdisciplinar de Acolhimento, denominado de "plantão psicológico". Posteriormente, são encaminhadas para os Grupos Interdisciplinares de Acompanhamento. Esses grupos são conduzidos por uma psicóloga, uma assistente social e uma advogada, as quais prestam, respectivamente, apoio emocional; atendimento aos direitos sociais; orientação, articulação e inclusão na rede de serviços e ingresso de ações na Vara de Família. Os Grupos acontecem quinzenalmente, com duração de 50 minutos e o tempo de permanência das mulheres varia de acordo com suas necessidades.

Os atendimentos lá prestados se pautam nas práticas dos profissionais que ali atuam, entretanto um estudo sistemático para verificar a eficiência 
dos atendimentos prestados ainda não havia sido realizado. A presente pesquisa teve como objetivo avaliar alguns aspectos da mudança apresentadas pelas mulheres assistidas na SOS Ação Mulher e Família, no enfrentamento da violência doméstica. Foram comparadas mulheres em fase inicial de atendimento com mulheres que já haviam concluído os atendimentos nesta instituição. Para tanto, foram avaliadas mudanças nos padrões de respostas adaptativas, na severidade dos sintomas psicopatológicos e nos estágios de mudança.

\section{Método}

Metodologicamente o estudo utilizou delineamento transversal, que se baseia na comparação entre dois ou mais grupos em estágios diferentes de um processo desenvolvimental ou em condições diferentes, "que, espera-se, são significativas para a mudança" (Breakwell, Hammond, Fife-Schaw \& Smith, 2010, p. 37).

\section{Participantes}

Compuseram a amostra, 18 mulheres vítimas de violência doméstica. 0 grupo pré-assistência ou Gr. 1 foi constituído por nove mulheres com idades entre 27 e 53 anos ( $M=36,7 ;$ d.p. = 8,68; $\mathrm{Me}=33$ ). 0 grupo pós-assistência ou Gr. 2, com mulheres entre 26 e 59 anos $(\mathrm{M}=41 ;$ d.p. $=11,28 ; \mathrm{Me}=40)$. Em relação à idade ( $\mathrm{M}=38$ anos) e ao nível de escolaridade (Ensino Médio), não houve diferenças significantes entre as amostras ( $p>0,10)$, o que indica que as amostras são comparáveis quanto a essas variáveis sociodemográficas (para estimar a diferença das participantes dos dois grupos quanto às variáveis, utilizou-se a prova de Fisher). Em relação ao estado civil, no Gr. 1 prevaleceram as casadas $(66,66 \%)$ e no Gr. 2 as solteiras $(66,66 \%)$, mas em ambos os casos as mulheres viviam "maritalmente", isto é, conviviam com o agressor.

Quanto ao registro de ocorrência, em ambos os grupos, a maioria registrou ao menos um boletim de ocorrência por agressão e/ou ameaça. A maioria da amostra sofria agressão recorrente e em relação ao tipo de violência, com exceção das duas participantes que foram vítimas de estupro, as demais sofreram mais de uma forma de violência perpetrada por parceiro íntimo. Quanto ao tempo médio (11 anos) que as participantes sofreram violência, não houve diferenças significativas entre as amostras. Os perfis sociodemográficos dos dois estratos amostrais se mostraram semelhantes, sugerindo que a utilização do delineamento do tipo transversal foi adequado.

\section{Instrumentos}

\section{Escala de Estágios de Mudança (EEM)}

É uma escala de autorrelato composta por 32 itens subdivididos em quatro grupos de oito itens, destinados a avaliar os estágios de mudança em que se encontra o indivíduo. Cada estágio reflete o nível de consciência de um problema e o esforço para enfrentá-lo. Os estágios de mudança são: pré-contemplação, contemplação, ação e manutenção. Para cada item são apresentadas possibilidades de respostas em escala do tipo Likert de cinco pontos que variam desde "discordo totalmente" (escore 1) até "concordo totalmente" (escore 5). A avaliação do estágio de mudança é dada pela maior pontuação nos itens de determinado estágio.

A EEM foi desenvolvida com o intuito de orientar o clínico quanto à disponibilidade do paciente para mudar atitudes ou comportamentos que estejam lhe causando algum tipo de conflito, sofrimento psicológico ou comprometendo sua saúde de maneira geral. Tem sido utilizada em intervenções para mudanças no hábito de beber, adição ao tabaco, e também em processos de psicoterapias. Resultados de várias pesquisas indicam as qualidades psicométricas da versão original do instrumento (McConnaughy et al., 1989; McConnaughy, Prochaska \& Velicer, 1983) e também a versão em português (Pace, 1999; Yoshida, Primi \& Pace, 2003).

\section{Escala de Avaliacão de Sintomas (EAS-40)}

É uma escala multidimensional de autorrelato composta por 40 itens, adaptada do Symptom Checklist - 90 - Revised (SCL-90-R), para pacientes clínicos de hospitais gerais. Esse instrumento é destinado à avaliação da severidade de sintomas psicopatológicos de acordo com quatro dimensões: Psicoticismo (referente a distúrbios graves, com sintomas de psicoticismo, hostilidade, ideias paranoides e depressão); Obsessividade-Compulsividade (sintomas

Psicol. Argum. 2013 jul./set., 31 (74), 415-423 
relacionados a pensamentos repetitivos, seguidos de desconforto nas relações interpessoais); Somatização (sintomas geralmente relacionados aos distúrbios somáticos e somatoformes); e Ansiedade (sintomas que vão de ansiedade generalizada a ansiedade fóbica direcionada a situação e objetos específicos).

As respostas são dadas em escala de tipo Likert de três pontos, em que 0 corresponde a nenhum sintoma, 1 a pouco sintoma e 2 a muito sintoma. 0 Índice Global de Severidade (IGS), derivado tanto do número quanto da intensidade dos sintomas, é um indicador do funcionamento psicológico. A EAS-40 demonstrou precisão de teste e reteste para diferentes amostras brasileiras, tais como, pacientes atendidos em serviços de saúde mental e em enfermarias com diversas doenças (Laloni, 2001) e estudantes universitários (Yoshida \& Silva, 2007), com coeficientes de correlação entre 0,40 a 0,93. Evidenciou boa consistência interna (de 0,73 a 0,88 ) e boa validade de construto (verificado por análise fatorial, análise de agrupamento e análise de correspondência) (Laloni, 2001). Outro estudo (Yoshida, 2008) indicou o escore 1 como ponto de corte dos quatro fatores desse instrumento para a população clínica.

\section{Escala Diagnóstica Adaptativa Operacionalizada Redefinida (EDAO-R)}

A escala possibilita, por meio de entrevista clínica, uma avaliação da qualidade da eficácia adaptativa medida segundo o grau de adequação das respostas de quatro setores da personalidade para a solução das dificuldades. São avaliados os seguintes setores: afetivo-relacional (A-R) - respostas emocionais do indivíduo nas relações interpessoais e na relação consigo mesmo; produtividade (Pr) respostas relacionadas ao trabalho, estudo ou qualquer ocupação principal do indivíduo; sociocultural (S-C) - respostas relacionadas à estrutura social, aos recursos comunitários, aos valores e costumes do ambiente em que vive; e orgânico (Or) — compreende o estado e funcionamento do indivíduo e cuidados e ações em relação ao próprio corpo. Nos setores S-C e Or, a avaliação é feita de forma qualitativa, e nos setores A-R e Pr as avaliações são realizadas de maneira quantitativa e qualitativa.

Para avaliar a qualidade da adaptação de cada setor, há três possibilidades: adequada, pouco adequada e pouquíssimo adequada. Respostas consideradas adequadas oferecem satisfação e o problema é solucionado sem existir conflitos intrapsíquicos ou socioculturais. Respostas pouco adequadas envolvem algum conflito, mesmo se existir algum grau de satisfação. Já nas respostas pouquíssimo adequadas a solução encontrada é insatisfatória e gera conflito externo e/ou interno. Uma vez avaliado cada um dos setores, tem-se cinco grupos de adaptação possíveis: adaptação eficaz (G1); adaptação ineficaz leve (G2); adaptação ineficaz moderada (G3); adaptação ineficaz severa (G4); adaptação ineficaz grave (G5). Nos casos "em crise", momentos em que o indivíduo não consegue dar respostas às situações críticas, acrescenta-se esta designação ao grupo adaptativo (Simon, 1997).

\section{Procedimento}

A coleta de dados foi realizada em sala cedida pela instituição. Todas as participantes responderam à EEM e à EAS-40 de maneira assistida (com a leitura dos itens pelo avaliador), e em seguida a primeira autora realizou uma entrevista semidirigida para avaliação da EDAO-R. As entrevistas foram gravadas e posteriormente transcritas. As autoras fizeram a avaliação da Eficácia Adaptativa de acordo com a EDAO-R, de forma independente. Na sequência, as avaliações de ambas foram comparadas, sendo alto o índice de acordo entre elas (80\%), o que garante a precisão das avaliações.

A participação foi voluntária e antecedida da assinatura do Termo de Consentimento Livre e Esclarecido. 0 projeto foi aprovado pelo Comitê de Ética da instituição (protocolo n. 979/09, de 1ำ de dezembro de 2009) e obteve a autorização do SOS Ação Mulher e Família para a realização da pesquisa.

\section{Resultados}

Os resultados de cada participante em relação a EEM, EAS-40 e EDAO-R são apresentados na Tabela 1. Também são informadas as médias, desvios padrão e medianas de cada grupo, quando cabível. Para verificar se os dois grupos diferiam proporcionalmente quanto aos resultados dos instrumentos utilizados foi aplicada a prova de Fisher.

Em relação à EEM, as participantes que estavam no estágio de Contemplação e Preparação, isto é, que ainda não apresentavam um movimento evidente de 
Tabela 1 - Resultados da EEM, EAS-40 e EDAO-R de cada participante do Gr. 1 e Gr. 2 e médias, desvio padrão e mediana de cada grupo

\begin{tabular}{|c|c|c|c|c|c|c|c|c|c|c|}
\hline \multicolumn{11}{|c|}{ Gr. 1 (Grupo pré-assistência) } \\
\hline \multirow{2}{*}{$\begin{array}{c}\text { Partici- } \\
\text { pante }\end{array}$} & \multirow[t]{2}{*}{ EEM } & \multicolumn{6}{|c|}{ EAS-40 } & \multicolumn{3}{|c|}{ EDAO-R } \\
\hline & & & $\mathbf{F 1}^{2}$ & F2 & F3 & $\mathbf{F 4}$ & IGS $^{3}$ & $A-R^{4}$ & Pr & $\begin{array}{l}\text { G. ADAP- } \\
\text { TAÇÃo }\end{array}$ \\
\hline 1 & $\mathbf{A}^{1}$ & & 0,4 & 0,4 & 0,2 & 0,3 & 0,32 & 1 & 1 & $\mathrm{G} 2^{5}$ \\
\hline 2 & A & & 0,1 & 0,9 & 1,6 & 0,6 & 0,8 & 1 & 0,5 & G5 \\
\hline 3 & A & & 1,7 & 2 & 1,8 & 1,8 & 1,8 & 1 & 0,5 & G5 \\
\hline 4 & $\mathbf{P}$ & & 1,2 & 1,8 & 1,1 & 1,5 & 1,4 & 1 & 0,5 & G5 \\
\hline 5 & $\mathbf{P}$ & & 1,5 & 1,6 & 1,4 & 1,5 & 1,5 & 1 & 1 & G4 \\
\hline 6 & C & & 1,1 & 1 & 1,4 & 0,3 & 0,95 & 1 & 0,5 & G5 \\
\hline 7 & $\mathbf{P}$ & & 0,8 & 1,1 & 1,1 & 0,7 & 0,92 & 2 & 0,5 & G4 \\
\hline 8 & C & & 1,2 & 1,8 & 0,5 & 0,5 & 1 & 1 & 0,5 & G5 \\
\hline \multirow[t]{4}{*}{9} & A & & 0,9 & 0,8 & 0,4 & 0,7 & 0,7 & 3 & 0,5 & G3 \\
\hline & & Média & 0,98 & 1,26 & 1,05 & 0,87 & 1,04 & & & \\
\hline & & d.p. & 0,5 & 0,55 & 0,56 & 0,56 & 0,45 & & & \\
\hline & & Mediana & 1,1 & 1,1 & 1,1 & 0,7 & 0,95 & & & \\
\hline \multicolumn{11}{|c|}{ Gr. 2 (Grupo pós-assistência) } \\
\hline \multirow{2}{*}{$\begin{array}{c}\text { Partici- } \\
\text { pante }\end{array}$} & EEM & \multicolumn{6}{|c|}{ EAS-40 } & \multicolumn{3}{|c|}{ EDAO-R } \\
\hline & & & F1 & F2 & F3 & F4 & IGS & A-R & $\operatorname{Pr}$ & $\begin{array}{c}\text { G. ADAPTA- } \\
\text { ÇÃo }\end{array}$ \\
\hline 10 & $P$ & & 0,5 & 0,8 & 0,6 & 0,9 & 0,7 & 2 & 1 & G3 \\
\hline 11 & $\mathrm{C}$ & & 0,9 & 1 & 0,7 & 0,4 & 0,75 & 3 & 2 & G1 \\
\hline 12 & $\mathrm{P}$ & & 0,9 & 1,8 & 1,3 & 1,6 & 1,4 & 1 & 0,5 & G5 \\
\hline 13 & $\mathrm{P}$ & & 0,4 & 0,8 & 0,1 & 0,6 & 0,47 & 2 & 2 & G2 \\
\hline 14 & $\mathrm{P}$ & & 1 & 1,5 & 1,7 & 1,2 & 1,35 & 1 & 0,5 & G5 \\
\hline 15 & $\mathrm{P}$ & & 0 & 0,1 & 0,2 & 0 & 0,07 & 3 & 2 & G1 \\
\hline 16 & A & & 0,1 & 0,8 & 0,6 & 0,9 & 0,6 & 3 & 2 & G2 \\
\hline 17 & $\mathrm{C}$ & & 0,6 & 0,5 & 0,7 & 0,4 & 0,55 & 2 & 2 & G2 \\
\hline \multirow[t]{4}{*}{18} & $\mathrm{C}$ & & 0,1 & 0,5 & 0 & 0,2 & 0,2 & 3 & 2 & G1 \\
\hline & & Média & 0,5 & 0,86 & 0,65 & 0,68 & 0,67 & & & \\
\hline & & d.p. & 0,38 & 0,5 & 0,55 & 0,5 & 0,45 & & & \\
\hline & & Mediana & 0,5 & 0,8 & 0,6 & 0,6 & 0,6 & & & \\
\hline
\end{tabular}

Legenda: ${ }^{1}$ Estágios de Mudança segundo a EEM: C = Contemplação; $\mathrm{P}=$ Preparação; A = Ação; M = Manutenção. ${ }^{2}$ Dimensões dos sintomas psicopatológicos segundo EAS-40: F1 = Psicoticismo; F2 = Obsessividade-Compulsividade; F3 = Somatização; F4 $=$ Ansiedade. ${ }^{3}$ IGS - Índice Global de Severidade. ${ }^{4}$ Setores da Personalidade segundo a EDAO-R: A-R = Afetivo-Relacional; $\operatorname{Pr}=$ Produtividade. ${ }^{5}$ Grupos de Adaptação segundo a EDAO-R: G1 = adaptação eficaz; G2 = adaptação ineficaz leve; G3 = adaptação ineficaz moderada; G5 = adaptação ineficaz grave.

Fonte: Dados da pesquisa.

mudança, foram comparadas às que se encontravam em estágio de Ação, indicativo de envolvimento na mudança. Não foram encontradas diferenças significantes entre os grupos $(p=0,14)$, sugerindo que estes se equivalem quanto ao estágio de mudança. Ressaltase que se observou, no decorrer das aplicações, falta de compreensão em alguns itens, o que pode de alguma maneira ter comprometido os resultados.

Quanto à intensidade dos sintomas psicopatológicos, o Índice Global de Severidade (IGS) da EAS40 variou de 0,32 a $1,8(\mathrm{M}=1,04, \mathrm{Me}=0,95)$ no Gr. 1 e de 0,07 a $1,4(M=0,67, M e=0,6)$ no Gr. 2 .

Psicol. Argum. 2013 jul./set., 31 (74), 415-423 
A comparação dos dois grupos foi realizada com base nas medianas. 0 resultado apontou diferença significante entre os grupos ( $p=0,027)$; ou seja, as participantes do Gr. 2 apresentaram sintomas menos severos quando comparadas às do Gr. 1 .

Para verificar se os dois grupos diferiam proporcionalmente quanto a cada dimensão da EAS-40, os grupos foram divididos em função da mediana. Foram encontrados os seguintes valores de p: 0,16 para F1 (psicoticismo); 0,16 para F2 (obsessividade-compulsividade); 0,04 para F3 (somatização); 0,34 para F4 (ansiedade). Isto é, apenas em relação à dimensão somatização houve diferença significante entre os grupos, com o Grupo pós-assistência (Gr. 2) apresentando, proporcionalmente, menos sintomas relacionados aos distúrbios somáticos e somatoformes.

Em relação à EDAO-R, esta aponta a capacidade de enfrentamento e adequação do indivíduo perante determinada situação. Para estimar a diferença entre as participantes dos dois grupos, fez-se a comparação do grupo diagnóstico em que se as participantes se encontravam no momento da avaliação. Para tanto, as amostras foram reunidas em adaptação eficaz (G1), ineficaz leve (G2) e ineficaz moderada (G3) e comparadas às que apresentavam adaptação severa (G4) e grave (G5). 0 resultado ( $p=0,027$ ) apontou que as participantes do Gr. 2 apresentaram proporcionalmente, melhor eficácia adaptativa, estando entre eficaz e moderada, quando comparadas com as do Gr. 1, em que predominaram as participantes com adaptação ineficaz severa ou grave.

Para verificar se os grupos diferiam proporcionalmente na qualidade da eficácia adaptativa em função dos setores da personalidade, afetivo-relacional (A-R) e produtividade (Pr) da EDAO-R, os mesmos foram divididos da seguinte maneira: adequado e pouco adequado vs. pouquíssimo adequado. 0 resultado obtido foi $\mathrm{p}=0,027$ tanto para o setor A-R quanto para o Pr. Os setores da personalidade segundo a EDAO-R também são apresentados na Tabela 1.

\section{Discussão}

Ao contrário do esperado, tanto o Gr. 1 quanto o Gr. 2 se distribuíram predominantemente nos estágios de mudança pré-contemplação e contemplação, caracterizados, respectivamente, pelo não reconhecimento ou não enfrentamento do problema. Esses dados contrastam com o fato de as participantes serem pessoas que foram em busca de ajuda e que, ao menos em tese, estão tentando solucionar o problema. Para tentar compreender essa aparente contradição, recorreu-se ao conteúdo das entrevistas clínicas.

Por meio de uma avaliação de cunho mais qualitativo, foi possível perceber um descompasso entre o desejo de mudar e a possibilidade efetiva de romper com antigos padrões mal adaptativos de conduta. Depois de anos vivendo com a agressão, as mulheres acabam por romper o silêncio quando não suportam mais, quando estão exaustas e quando se dão conta de que sozinhas não conseguem pôr fim às agressões e nem transformar o comportamento do companheiro (Costa, Ribeiro \& Moreira, 1992, citados por Jacobucci, 2004). No entanto, para conseguir acessar um novo estágio de mudança, essas mulheres têm de ser capazes de enfrentar a presença de poderosas emoções negativas tais como medo e insegurança, que atuam como freios ou obstáculos para assumirem um papel mais proativo de suas vidas. Ademais, o fato de o agressor ser um conhecido íntimo aumenta a sensação de vulnerabilidade e fragilidade, deixando as mulheres mais propensas a aceitarem a vitimização e com menos possibilidade de se protegerem (Giffin, 1994; Heise, 1994).

Nesse sentido, são ilustrativas as seguintes afirmações: "É como se estivesse tudo fechando ... eu vejo que eu estou sem estrutura nenhuma, eu me vejo sem chão" (participante 3 - Gr. 1); ou "Eu vim aqui porque eu precisava de ajuda, nossa eu tava com medo, sem esperança nenhuma sabe, sem saber pra onde eu ia, o que eu ia fazer..." (participante 15 - Gr. 2). Também se observa o peso de valores culturais muito desvantajosos para o progresso na mudança, como fica claro na seguinte afirmação: "Mas assim, é muito forte, eu sempre pensei assim, casamento é para vida toda, enfrentar as dificuldades junto a vida toda, sabe?" (participante 17 - Gr. 2).

Outro possível motivo para a ausência de diferença quanto ao estágio de mudança entre os dois grupos pode estar ligado ao período muito breve dos atendimentos prestados pela instituição (de um a seis meses).Segundo Prochaska (1995), quando o paciente encontra-se no estágio de contemplação, a frequência semanal das sessões é desejável e uma terapia de longo prazo é o mais recomendado. Há, portanto, coincidência entre os resultados obtidos e o desejo por parte das mulheres que verbalizam claramente a necessidade de continuação dos atendimentos. A participante 6 (Gr. 1), por exemplo, ao término da entrevista clínica 
solicitou à pesquisadora novos atendimentos psicológicos, manifestou claramente seu desejo em retomar o acompanhamento com a psicóloga, justificando que ainda existiam aspectos de sua vida que não estavam completamente resolvidos. Outro exemplo é a participante 11 (Gr. 1): "Ficou assim entre aspas umas áreas que não chegou ali naquela conclusão que talvez eu esperava que fosse chegar. Precisava de mais um tempo nas consultas, né?"

Por outro lado, há que se observar que as mulheres do Gr. 2 participaram do presente estudo, em média, quatro meses após terem sido assistidas pela instituição. E, nesse sentido, é possível que os resultados revelem uma eventual falta de persistência da mudança verificada por ocasião do término dos atendimentos. Pesquisas envolvendo a avaliação de um grupo que tenha concluído recentemente os atendimentos ou com delineamento longitudinal poderão responder mais apropriadamente a essa questão. Por ora pode-se apenas afirmar que mulheres que concluíram seus atendimentos no SOS Mulher e Família há cerca de quatro meses tendem a se encontrar nos estágios de mudança contemplação e preparação. Além disso, elas não se diferenciam, a esse respeito, das que se encontram em fase inicial de atendimento.

Em relação ao nível de severidade dos sintomas psicopatológicos, as participantes do Gr. 2 apresentaram Índices Globais de Severidade na EAS-40 menos severos que as do Gr. 1, sugerindo que os atendimentos teriam propiciado uma melhora nos sintomas psicopatológicos. No entanto, quando analisadas as diferenças entre os dois grupos com base nas dimensões da EAS-40, constatou-se que elas eram significantes apenas para a dimensão somatização (F3), em que o Gr. 2 apresentava sintomas menos severos. Nas demais dimensões ambos os grupos exibiam sintomas considerados severos.

Nas entrevistas clínicas ficou evidente o sofrimento devido a ansiedade elevada, ocorrência de pensamentos e ações repetitivas, desconforto nas relações interpessoais e isolamento, sintomas característicos das dimensões psicoticismo (F1), obsessividade-compulsividade (F2) e ansiedade (F4), especialmente entre as participantes do Gr. 1. As seguintes afirmações dão uma ideia da presença desses sintomas: “... eu sempre fui uma pessoa muito sozinha, não tenho amizades com vizinhos, não porque eles não quer, mas porque eu não confio" (participante 7 Gr. 1); “Tem que tá sempre com aquele medo, sabe?
Sempre vigilante, porque a qualquer hora ele pode chegar na minha casa numa boa, ou ele já chega chutando o portão, xingando, falando palavras de baixo calão, ameaçando e daí por diante" (participante 9 Gr. 1).

Ainda, as participantes deixavam clara a presença de baixa autoestima e pouca confiança em si mesmas e nos outros. Alguns exemplos: "É difícil pra mim, eu não tenho mais amor nenhum, não tenho vontade de mais nada ... eu me sinto muito mal, me sinto uma covarde mesmo" (participante 4 - Gr. 1). Outras relataram tentativas de suicídio, coincidindo com os resultados de Tavares (2000): "Foi várias tentativas de suicídio ... eu achava que tava de mãos atadas e isso me corroia por dentro. Ai eu comecei a perceber que não tinha saída e eu comecei as tentativas, várias e de várias maneiras" (participante 7 - Gr. 1). De acordo com diferentes pesquisas, há uma relação de risco entre a experiência da violência e o desenvolvimento de agravos, de ordem física e mental e, portanto, uma relação direta com a severidade dos sintomas psicopatológicos. Quanto às experiências de ordem mental, prevalecem medo, isolamento social, dependência emocional, sentimentos de culpa e tentativas de suicídio, como graves sequelas psicológicas (Camargo, 2000; Day et al., 2003; Jacobucci, 2004; Schraiber, D’Oliveira \& Couto, 2006; Silva, Coelho \& Caponi, 2007).

Apesar de as participantes do Gr. 2 continuarem com níveis clínicos de sintomas psicopatológicos em algumas dimensões da EAS-40, apresentaram melhor eficácia adaptativa de acordo com a EDAO-R. Como referido, elas apresentavam adaptação entre eficaz e ineficaz moderada, enquanto que entre as do Gr. 1 predominaram adaptações ineficazes severa e grave. Essas dificuldades se estendiam ao setor da Produtividade, que ficava prejudicado possivelmente devido ao comprometimento afetivo-emocional das participantes, que se estendia para todas as áreas de funcionamento. Esses resultados sugerem que as mulheres que acorrem ao SOS necessitam de intervenções que as ajudem a desenvolver meios adaptativos eficazes para enfrentarem seus problemas e saírem dessa condição de vítimas de violência.

Resumindo, pode-se dizer que apesar de as participantes do Gr. 2 apresentarem um quadro mais benigno em termos de sintomas psicopatológicos e da configuração adaptativa, elas ainda se mantinham em patamares críticos que requeriam cuidados,

Psicol. Argum. 2013 jul./set., 31 (74), 415-423 
especialmente, de natureza psicológica. Nesse sentido, o oferecimento de sessões específicas de psicoterapia e por um período mais prolongado pode ser uma alternativa de assistência para a demanda existente. Ademais, pesquisas sistemáticas de avaliação de resultado, de curto e médio prazo, podem ajudar a ajustar a estratégia mais eficiente de atendimento.

Possivelmente a avaliação dos Estágios de Mudança seja uma alternativa mais adequada do que o emprego da EEM (Yoshida, 2002), em estratos da população com baixa escolaridade, uma vez que, conforme referido, houve dificuldade de compreensão, por parte de algumas participantes.

\section{Considerações finais}

Apesar do tamanho reduzido da amostra e das limitações do delineamento metodológico empregado (transversal em vez de longitudinal), os resultados corroboram os de outros estudos com mulheres vítimas de violência. Essas investigações mostram que essas mulheres chegam à instituição com vários comprometimentos, com confusão de pensamentos, e não acreditam que o problema tem solução ou que alguém possa ajudá-las (Jacobucci, 2004; Tavares, 2000). Além disso, muitas ainda consideram-se culpadas por seu sofrimento, o que funciona como um obstáculo ao processo de mudança.

Em face da magnitude dos problemas, é necessário que as instituições que prestam atendimento a essa população estejam preparadas para oferecer, além do atendimento jurídico e social, adequada assistência psicológica, o que, segundo a experiência clínica das pesquisadoras e de dados da literatura, supõe atendimento semanal durante, pelo menos, um ano (Prochaska, 1995). Sabe-se das dificuldades e condições, muitas vezes precárias, dessas instituições, com toda sorte de restrições, tais como, orçamentária, de pessoal qualificado, entre outras. No entanto, é de suma importância que se tenha clareza das necessidades para que se continue lutando por formas mais eficientes de atendimento.

Cabe assinalar como uma das principais limitações do presente estudo, o fato de ele ter baseado a avaliação de mudança em amostras distintas e não ter contado com o acompanhamento longitudinal das participantes. Deve-se ainda mencionar o tamanho reduzido das amostras que prejudica a generalização dos resultados, e o fato de que algumas das participantes mostraram falta de compreensão em alguns itens e enumerados da EEM, o que pode de alguma forma ter comprometido os resultados.

Apesar das limitações, acredita-se que o estudo tenha contribuído para a reflexão em torno do enfrentamento de um dos grandes problemas sociais da atualidade, que é o da violência contra as mulheres. Ademais, em relação especificamente à psicologia, modalidades de intervenção mais adequadas e eficientes devem continuar a ser pesquisadas, de forma que a assistência oferecida seja a mais eficaz possível. Dentre elas, citam-se as psicoterapias breves que permitem examinar situações-problema específicas (Simon, 1989), de forma aprofundada, num curto espaço de tempo (Yoshida, 2008). Pesquisas de acompanhamento dessas intervenções poderão apontar a eficiência dessa modalidade de atendimento, na ajuda a mulheres vítimas de violência, quanto à superação dos sofrimentos psíquicos a que estão sujeitas.

\section{Referências}

Bandeira, L. (2009). Três décadas de resistência feminista contra o sexismo e a violência feminina no Brasil: 1976 a 2006. Sociedade e Estado, 24(2), 401-438.

Breakwell, G. M., Hammond, S., Fife-Schaw, C., \& Smith, J. A. (2010). Métodos de pesquisa em psicologia. (3. ed.). Porto Alegre: Artmed.

Camargo, M. (2000). Violência e saúde: Ampliando políticas públicas. Jornal da Rede Saúde, 22, 6-8.

Cortizo, M. D. C., \& Goyeneche, P. L. (2010). Judiciarização do privado e violência contra a mulher. Revista Katálysis, 13(1), 102-109.

Dantas, B. M., \& Méllo, R. M. (2008). Posicionamentos críticos e éticos sobre a violência contra as mulheres. Psicologia \& Sociedade, 20, 78-86.

Day, P. D., Telles, E. B., Zoratto, P. H., Azambuja, M. R. F., Machado, D. A., Silveira, M. B., Debiaggi, M., Reis, M. G., Cardoso, R. G., \& Blank, P. (2003). Violência doméstica e suas diferentes manifestações. Revista de Psiquiatria do Rio Grande do Sul, 25(Supl. 1), 9-21.

Giffin, K. (1994). Violência de Gênero, Sexualidade e Saúde. Caderno de Saúde Pública, 10(1), 146-155. 
Heise, L. (1994). Gender-based abuse: The global epidemic. Caderno de Saúde Pública, 10(1), 135-145.

Jacobucci, P. G. (2004). Estudo psicossocial de mulheres vítimas de violência doméstica, que mantêm o vínculo conjugal após terem sofrido as agressões. Dissertação de Mestrado em Ciências Médicas, Universidade EstadualdeCampinas,Campinas. Recuperadoem 6 set. 2013, de http://libdigi.unicamp.br/document/?code =vtls000318255

Laloni, D. T. (2001). Escala de avaliação de sintomas-90-R SCL-90-R: Adaptação, precisão e validade. Tese de Doutorado em Psicologia, Pontifícia Universidade Católica de Campinas, Campinas. Recuperado em 6 set. 2013, de http://www.bibliotecadigital.puc-campinas.edu.br/tde_busca/arquivo.php?codArquivo=294

McConnaughy, E. A., Prochaska, J. O., \& Velicer, W. F. (1983). Stages of change in psychotherapy: Measurement and samples profiles. Psychotherapy: Theory, Research \& Practice, 20(3), 368-375.

McConnaughy, E. A., DiClemente, C. C., Prochaska, J. O., \& Velicer, W. F. (1989). Stages of change in psychotherapy: A followup report. Psychotherapy: Theory, Research \& Practice, 26(4), 494-503.

Pace, R. (1999). Escala de estágios de mudança: Variáveis psicométricas. Dissertação de Mestrado não publicada, Pontifícia Universidade Católica de Campinas, Campinas.

Pougy, L. G. (2010). Desafios políticos em tempos de Lei Maria da Penha. Revista Katálysis, 13(1), 76-85.

Prochaska, J. O. (1995). An eclectic and integrative approach: Transtheoretical therapy. In A. S. Gurman \& S. B. Messer (Ed.). Essential psychotherapies: Theory and practice. (pp. 411-443). New York: Guilford.

Schraiber, L. B., D’Oliveira, A. F. P. L., \& Couto, M. T. (2006). Violência e saúde: Estudos científicos recentes. Revista de Saúde Púbica, 40(n. especial), 112-120.

Silva, L. L., Coelho, E. B. S., \& Caponi, S. N. C. (2007). Violência silenciosa: Violência psicológica como condição da violência física doméstica. Interface (Botucatu), 11(21), 93-103.

Simon, R. (1989). Psicologia clínica preventiva. São Paulo: EPU.

Simon, R. (1997). Proposta de redefinição da EDAO (Escala Diagnóstica Adaptativa Operacionalizada). Boletim de Psicologia, 47(107), 85-94.
Tavares, D. M. C. (2000). Violência doméstica: Uma questão de saúde pública. Dissertação de Mestrado em Saúde Pública, Universidade de São Paulo, São Paulo. Recuperado em 6 set. 2013, de http://bvsms.saude. gov.br/bvs/ct/pdf/dinalva.pdf

Yoshida, E. M. P. (2002). Escala de estágios de mudança: Uso clínico e em pesquisa. Psico-USF, 7(1), 59-66.

Yoshida, E. M. P. (2008). Significância clínica de mudança em processo de psicoterapia dinâmica breve. Paidéia Ribeirão Preto, 18(40), 305-316.

Yoshida, E. M. P., Primi, R., \& Pace, R. (2003). Validade da escala de estágios de mudança. Estudos de psicologia, 20(3), 7-21.

Yoshida, E. M. P., \& Silva, F. R. C. S. (2007). Escala de Avaliação de Sintomas-40 (EAS-40): Validade e precisão em amostra não clínica. Psicologia Escolar $e$ Educacional, 11(1), 89-99.

Psicol. Argum. 2013 jul./set., 31 (74), 415-423 